\title{
INFLUENCE OF PARAMETERS OF MILLING PROCESS ON THE ENERGY CONSUMPTION OF THE MACHINE TOOL
}

\author{
Wojciech Borkowski ', Wacław Skoczyński', Paweł Piórkowski', Tomasz Jankowski ${ }^{1}$, \\ Andrzej Roszkowski', Michał Foremniak'
}

\begin{abstract}
1 Wrocław University of Technology and Science, Faculty of Mechanical Engineering, Łukasiewicza 5, 50-370 Wrocław, Poland, e-mail: wojciech.borkowski@pwr.edu.pl, waclaw.skoczynski@pwr.edu.pl, pawel. piorkowski@pwr.edu.pl, tomasz.jankowski@pwr.edu.pl, andrzej.roszkowski@pwr.edu.pl,michal.foremniak@ pwr.edu.pl
\end{abstract}

Received: 2018.04.28

Accepted: 2018.06.18

Published: 2018.09.01

\begin{abstract}
The article discusses the importance of energy consumption for the modern machine tool. The research was carried out to show the influence of various cutting factors and parameters on the power consumption values of the machine tool. A special algorithm was developed to determine the actual energy consumption of the machine tool during the cutting process. The results of the study were compared with the algorithms of tool companies to determine the machine's power demand. The possibilities of using research conclusions to develop a more accurate method for assessing the energy demand of a machine tool in the cutting process were indicated.
\end{abstract}

Keywords: energy consumption, machine tools, machining process, energy efficiency.

\section{INTRODUCTION}

Energy saving and ecology are becoming increasingly desirable aspects in modern technology. It is similar in the field of machine tools, where more and more focus is placed not only on the accuracy and efficiency of machining, but also on the energy consumption of the cutting process. One of the basic features that should characterize the ecological machine tool is to use as little energy as necessary to perform main and auxiliary movements [3]. In such circumstances, scientists are faced with the challenge of determining the factors affecting the amount of energy consumed by the machine and the method of data acquisition of the energy consumption during cutting process.

In recent years, a significant increase in electricity demand has been observed, which is not only due to population growth, but also because of their growing needs [7]. In the last century 17-fold increased demand for electricity was detected, while there was only 6-fold increase in the num- ber of people [8]. A significant part of this energy is consumed by the manufacturing industry, especially in the field of machine tools production. In the US, it absorbs $31 \%$ of the demand of the whole industry in the consumption of electricity [1].

Tool companies provide applications that allow estimating the energy demand of the machine tool during machining. These applications, however, are not able to determine the exact energy demand of the machine tool, they only give approximate values. In order to get more accurate information about the energy needs of the machine, it is necessary to measure it directly on the machine during the test cutting process. Such data take into account not only the influence of cutting process parameters during the machining, but also factors related to the machine tool. The parameters of the milling process in various ways affect the energy consumption of the machine tool. Their selection is related both to the machining capabilities of the machine, including its efficiency, and the tools used during the cutting process. Increasing machining 
parameters usually results in an increase in energy consumption but allows to process a larger volume of material per unit of time. Therefore, there are approaches that allow to change the developed technological process or cutting parameters so that the machining is the most energy-efficient $[2,4,5]$. The individual components of the electrical signal are analyzed to a greater extent in order to better evaluate the data related to the energy consumption of the machine tool $[6,9]$.

\section{MEASURING METHOD AND DATA ACQUISITION}

For data acquisition, the PQM-7012 power quality analyzer from Sonel was used (Fig. 1). The analyzer allows to measure both voltages and currents, as well as active and reactive power with the sampling frequency set by the user.

In the case of individual measurements, it is possible to determine the beginning and end of the cutting test based on the timeline, which allows to determine the basic parameters related to the energy consumption of the cutting process. In the case of a larger number of repeated measurements, there is a problem with the proper analysis of data.

An application was developed to automatically identify the cutting process in the signal received from the power quality analyzer. The user only verifies the correctness of the application's operation by observing the graphs of energy or power waveforms generated as a function of time. Utilization of this application allows to quickly obtain data for further analysis. The data obtained in this way can then be analyzed in any program, because the outcome of the application is a file with the .txt extension.

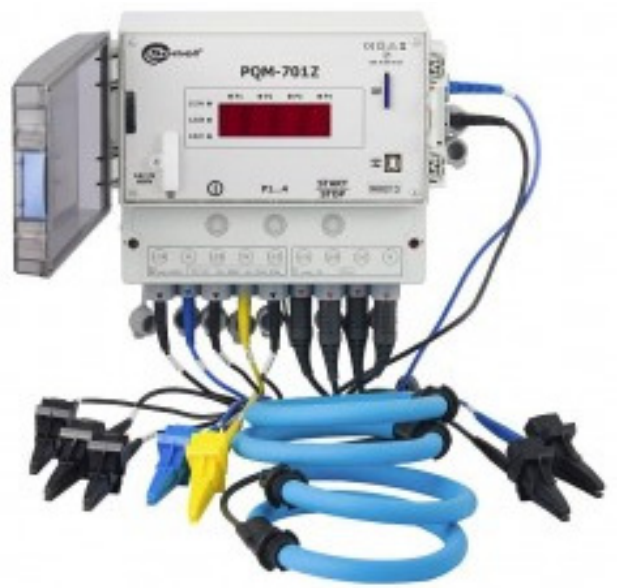

Fig. 1. Power quality analyzer - Sonel PQM-7012

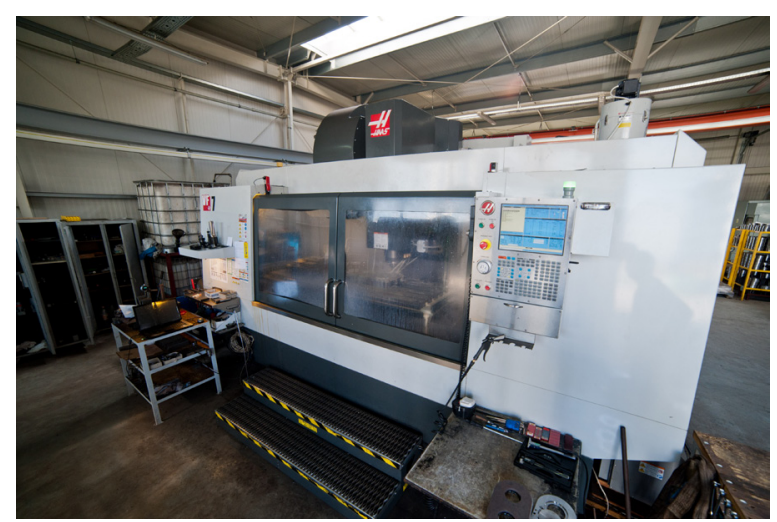

Fig. 2. Vertical milling center HAAS VF-7/50

\section{METHODOLOGY}

The aim of the research was to determine the effect of cutting parameters on the energy consumption of the milling process on the vertical milling center, and then to compare these results with the values that can be obtained in the applications of tool manufacturers. To complete the research goal, 100 cutting tests were planned to determine the relationships between the cutting process parameters. It was concurred that the trials would be carried out for the full spectrum of spindle load capabilities of the machine tool. The vertical milling center VF-7/50 (Fig. 2) was selected for the tests, with a maximum spindle speed of $7500 \mathrm{rpm}$ and a maximum torque of $460 \mathrm{Nm}$.

Four different tool diameters were selected: $25,40,63$ and $80 \mathrm{~mm}$. Due to the construction of the milling heads, each tool was equipped with a different number of cutting inserts, respectively 2,3,5 and 6 pieces. The material selected was C45 $+\mathrm{N}$, while the cutting inserts were Sandvik R3901704.16M-PM 4240. It was determined that the analyzed cutting parameters would be the milling width as a function of the tool diameter and the cutting speed. It was established that the tests will be carried out for five different cutting speeds: 160 , 200, 240, 280 and $320 \mathrm{~m} / \mathrm{min}$ and for five milling widths: $10,25,50,75$ and $100 \%$ of the tool diameter. Taking into account four different tool diameters, the total number machining trials was 100 .

The remaining cutting parameters were set as constant:

- Feed per tooth $\mathrm{f}_{\mathrm{z}}=0,15[\mathrm{~mm}]$

- Depth of cut $a_{p}=3[\mathrm{~mm}]$

- Length of cutting path $\mathrm{LS}=300[\mathrm{~mm}]$

The length od lead in and lead out of the tool were determined to gain data on the power con- 


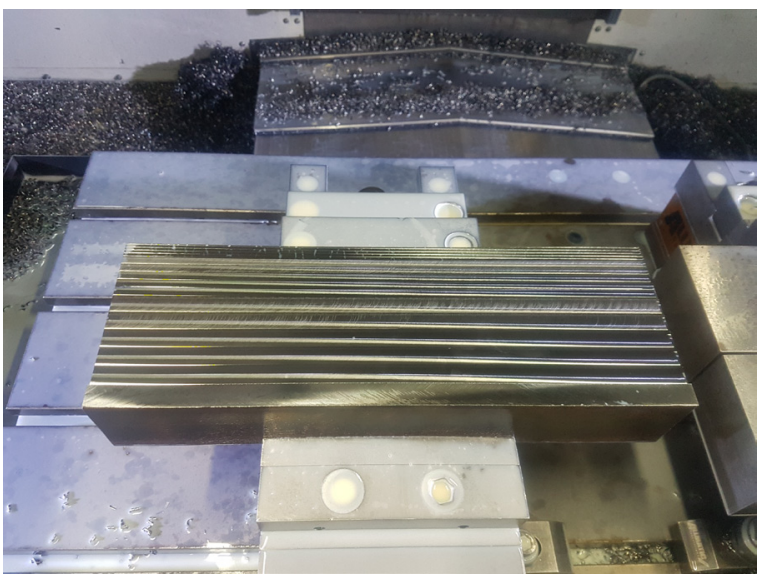

Fig. 3. Plate used for cutting tests prior to surface milling

sumed by the machine during the work movement without cutting the material. After each test, the roughness of the machined surface was measured. As a result of the cutting parameters adopted, the spindle was loaded in the range from 2 to $95 \%$ of its maximum capabilities. Machining tests were performed on a plate with initial dimensions of $58 \times 120 \times 320 \mathrm{~mm}$ (Fig. 3).

After each cutting test carried out on the entire surface of the plate, the milling head was used to even inequalities of the plane, and then the cutting tests continued.

\section{TEST RESULTS}

The following values were determined for each of the tests carried out:

- power consumption of the machine tool [W]

- average power [W]

- energy consumption per unit of volume [Wh/ $\mathrm{cm}^{3}$ ]

- power during lead in move [W]

- difference between average power and power during lead in move [W], referred to below as "cutting power"

- difference between total energy and energy during lead in move [Wh], referred to below as "cutting energy"

- share of cutting energy in total energy consumption [\%]

- cutting energy per unit of volume $\left[\mathrm{Wh} / \mathrm{cm}^{3}\right]$, referred to below as "cutting capacity"

In addition, surface roughness tests were also carried out (Fig. 4) using a Mitutoyo SJ-201 portable surface roughness tester.

There were no significant differences between the roughness meter indications neither the ma-

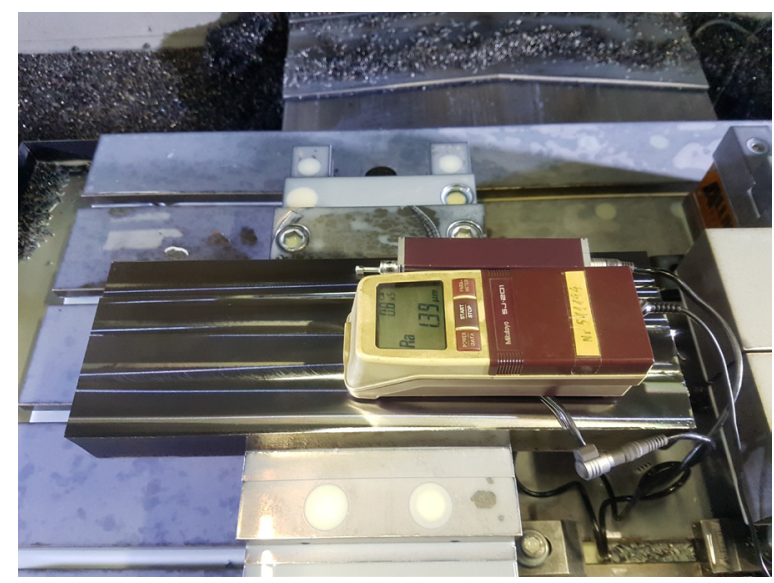

Fig. 4. Portable surface roughness tester SURFTEST Mitutoyo SJ-201

chining parameters used nor the spindle load. No Ra parameter exceeded $2 \mu \mathrm{m}$ in any of the trials.

\section{THE INFLUENCE OF THE TOOL DIAMETER ON THE ENERGY CONSUMPTION OF THE MACHINE TOOL}

Energy consumption of the machine tool, with different tool diameters used, varied depending on the cutting width parameter. For a cutting width of $10 \%$ of the tool diameter, energy consumption of machine tool was similar for each tool used. (Fig. 5) For larger cutting widths, clear differences were observed (Fig. 6). There was no evident effect of the change of cutting speed on energy consumption at different tool diameters used. For a cutting width of $10 \%$ of the tool diameter, the lowest energy consumption was observed for different milling heads depending on the cutting speed, but the differences between the

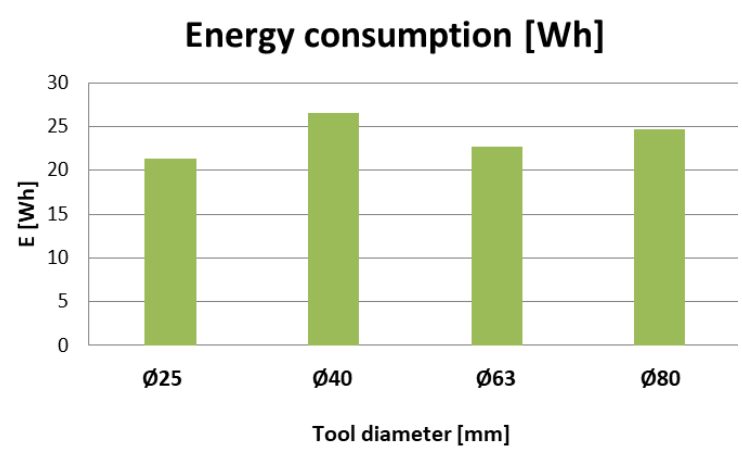

Fig. 5. Energy consumption [Wh] at a cutting speed of $160 \mathrm{~m} / \mathrm{min}$ and a cutting width of $10 \%$ of the tool diameter 


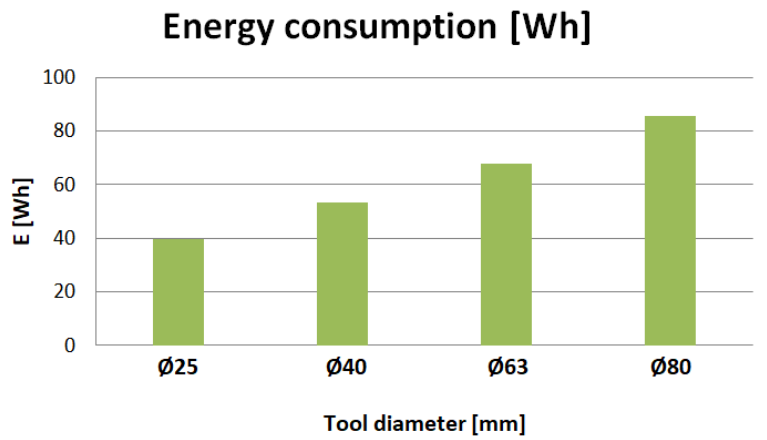

Fig. 6. Energy consumption [Wh] at a cutting speed of $160 \mathrm{~m} / \mathrm{min}$ and a cutting width of $100 \%$ of the tool diameter

results were negligible. For larger cutting widths, energy consumption was linearly dependent on the diameter of the tool.

After taking into account the volume of the processed material, it can be noticed that the increase in the diameter of the tool is beneficial from the viewpoint of energy consumption of the machine tool (Fig. 7), however, the larger the diameter, the differences in the results are smaller.

A significant part of the total energy during the cutting process is not related to the milling itself. The increase in power consumption during the entry of the tool into the machined material ranged from several to several dozen percent. The cutting energy increased significantly as the tool diameter and the cutting witdh increased (Fig. 8).

The tests carried out show that the cutting energy changes with the change in the tool diameter and the percentage of cutting width associated with it. The use of tools with large diameters and high cutting widths allows for lower energy consumption per unit volume during milling processes.

\section{Energy consumption per volume unit [Wh / cm3]}

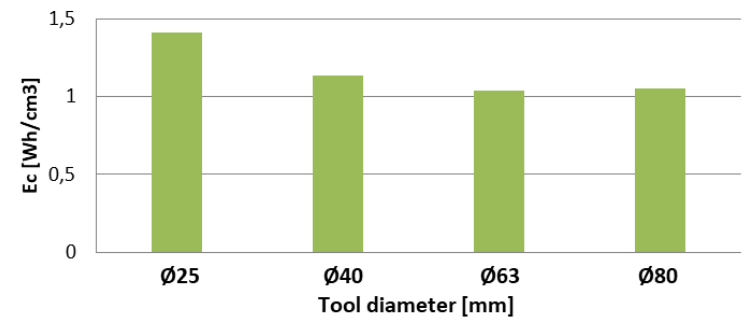

Fig. 7. Energy consumption per volume unit [Wh $/ \mathrm{cm} 3$ ] at cutting speed of $320 \mathrm{~m} / \mathrm{min}$ and cutting width $100 \%$

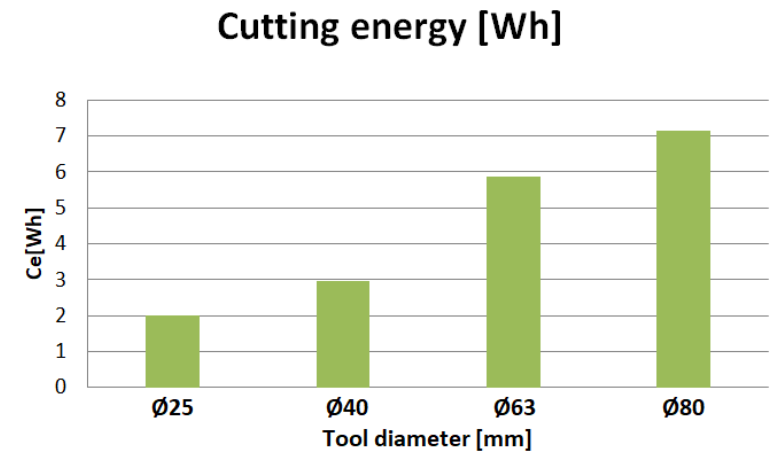

Fig. 8. Cutting energy at a cutting speed of $160 \mathrm{~m} /$ min and cutting width $10 \%$ of the tool diameter

\section{EFFECT OF WIDTH OF CUTTING ON THE ENERGY CONSUMPTION OF THE MACHINE TOOL}

The variable cutting width at constant tool diameter and cutting speed has a significant impact on the energy consumption of the machine tool. When analyzing the data for the average power consumption by the machine tool, it can be observed that an increase in the cutting width results in an escalation in the average power consumption (Fig. 9).

The increase in average power consumption, disproportionate to the cutting width, results from the fact that a part of the power is taken regardless of the occurrence of machining operations. It includes auxiliary elements of machine tool such as coolant pump, venting system of electrical cabinet etc. After not taking into account this power components, the dependence of the cutting width on the machine tool's power consumption is almost linear (Fig. 10).

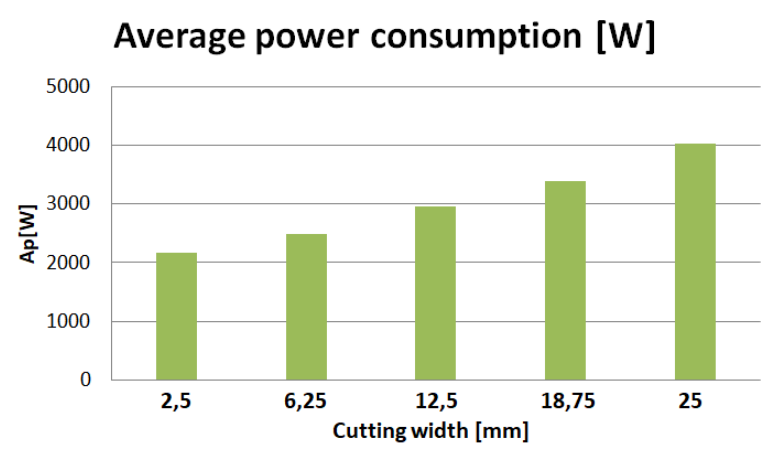

Fig. 9. Average power consumption [W] at cutting speed $160 \mathrm{~m} / \mathrm{min}$ and tool diameter $\Phi 25$ 


\section{Cutting power [W]}

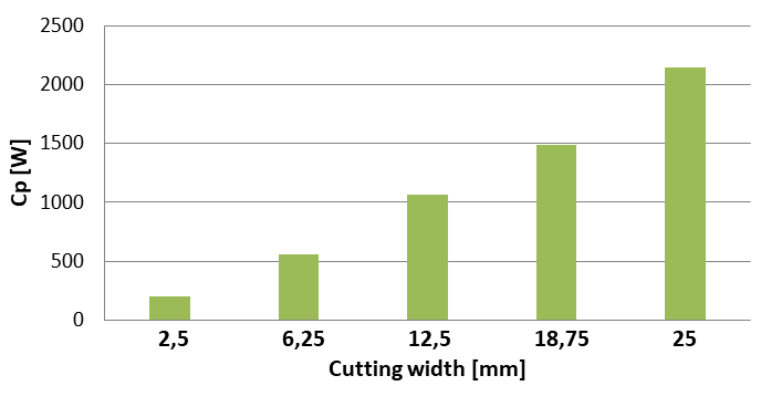

Fig. 10. Cutting power at a cutting speed of $160 \mathrm{~m} /$ min and tool diameter $\Phi 25$

\section{EFFECT OF CUTTING SPEED ON THE ENERGY CONSUMPTION OF THE MACHINE TOOL}

The increase in the cutting speed, without changing another milling parameters, results like in the case of the cutting width, in the rise in power consumption. Changes in the measured quantities after subtracting the part of the power that occurs outside the cutting process proceeded approximately linearly (Fig. 11).

The cutting energy in the case of variable cutting speed changes to a small extent and is more or less constant. For all tested tool diameters and milling widths, the changes in cutting energy resulting from the variable cutting speed ranged from a few to a dozen or so percent (Fig. 12).

\section{OTHER FACTORS AFFECTING ENERGY CONSUMPION OF THE MACHINE TOOL}

During the test, it was also shown that the method of transmission in the machine tool has an impact on its energy consumption. The exam-

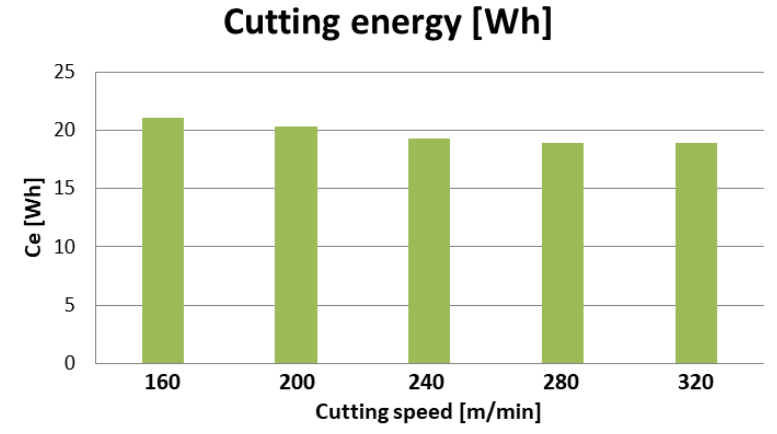

Fig. 12. Cutting energy with a cutting width of $25 \mathrm{~mm}$ and a tool diameter of $25 \mathrm{~mm}$

ined cutting machine drove the spindle using two gears. The first gear worked to $2000 \mathrm{rpm}$, while the second gear was used above this speed. The result was a changing permissible and percentage load on the spindle. In addition, the spindle load in the case of 1 st gear rised with decreasing rotational speed, while in the case of the 2nd gear it increased with growing rotational speed (Fig. 13).

After observing this relationship, it was decided to perform additional tests to determine the value of power consumed by the engine on 1 st and 2 nd gear. Three machine tool trials were carried out without cutting: without a tool, with a tool with a diameter of $11.5 \mathrm{~mm}$ and a tool with a diameter of $125 \mathrm{~mm}$, to determine the effect of the tool weight on the power consumption of the machine tool (Fig. 14).

It was observed that the weight and diameter of the tool mounted in the spindle has no effect on the power consumed by the machine tool during its operations. Small differences could be observed only when accelerating the spindle to the working speed. Both on the 1st and 2nd gear, the power consumption increases with the gain of the

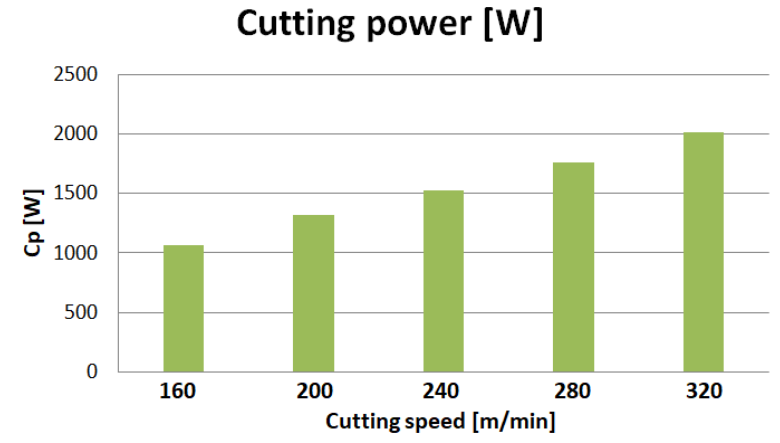

Fig. 11. Cutting power with a cutting width of 2.5 $\mathrm{mm}$ and a tool diameter of $\Phi 25 \mathrm{~mm}$

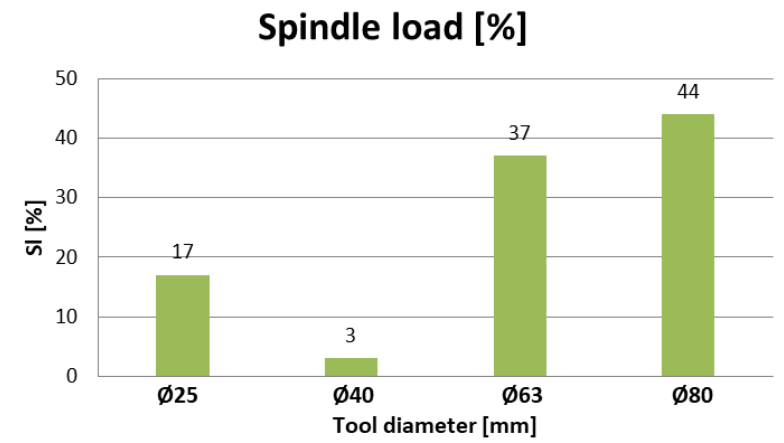

Fig. 13. Spindle load [\%] for cutting speed $160 \mathrm{~m} /$ min and cutting width equal to $10 \%$ of tool diameter 
Power consumed by the vertical milling centre VF-7/50

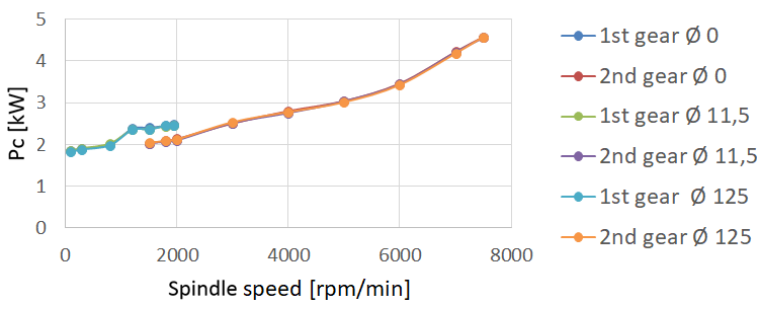

Fig. 14. Power consumed by the vertical milling center VF-7/50 on 1st and 2nd gear without a mounted tool and with tools diameters of 11.5 and $125 \mathrm{~mm}$

rotational speed. In the range 1300-2000 rpm, in which the machine tool can work in both gears, it was found that the lower power consumption occurs in the 2 nd gear. This relationship does not change linearly with the increase of the rotational speed and depends on the design solutions used in the machine tool. This information is important in determining the energy demand of the machine tool to complete the technological process.

During cutting trials where the spindle was loaded in the range of $70-100 \%$ of its maximum load, power measurement had serious disturbances that could affect the result of total power consumption. Over a 20 -second cutting test with a tool with a diameter of $80 \mathrm{~mm}$, a cutting width of $80 \mathrm{~mm}$ and a cutting speed of $320 \mathrm{~m} / \mathrm{min}$, the spindle load exceeded $100 \%$ for a while, and during most of the time the trial was maintained at $95 \%$. As a result, power consumption was unevenly distributed (Fig. 15).

For the first 8 seconds of milling the power consumption was very uneven, after about 9-10 seconds it stabilized. A similar problem was not observed when exiting the tool from the mate-

\section{Cutting power curve versus time}

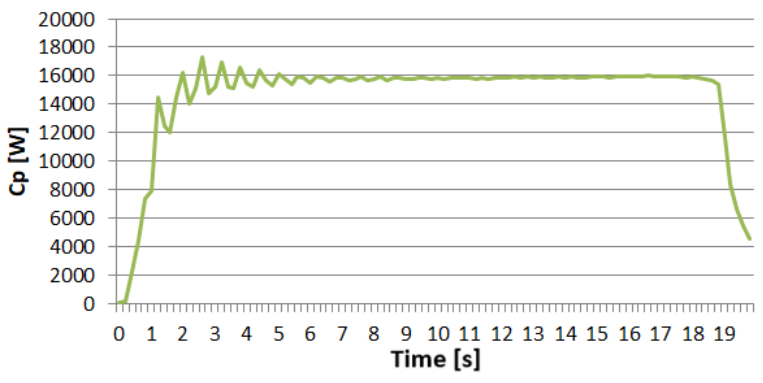

Fig. 15. Cutting power curve versus time during cutting with a spindle load of $95 \%$
Cutting capacity [Wh/cm3]

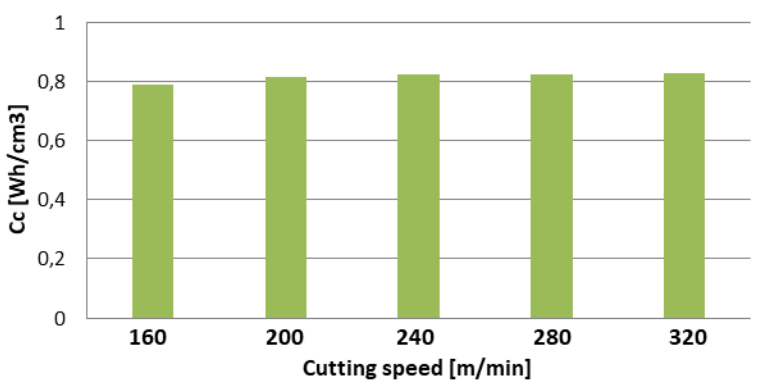

Fig. 16. Cutting capacity [Wh / cm3] for a cutting width of $20 \mathrm{~mm}$ and a tool diameter of $80 \mathrm{~mm}$

rial. Unevenness caused by excessive load on the spindle can affect the power consumption of the machine tool.

During the trials, for each of the 100 tests, the cutting performance was determined by comparing the cutting energy to the material volume, which was processed during the measurement. Some of the tests were carried out for the cutting speed not recommended by the manufacturer of the cutting inserts. After omitting these trials, 60 cutting results were obtained for the actual cutting data used in industry.

After analyzing the results, it turned out that the cutting capacity was almost equal in all 60 cutting tests and its value varied from 0.77 to 0.93 [Wh / cm3], which means a difference of several percent. These differences are smaller than changes in power consumption between processes using a new and used tool, and therefore are very small. Even large changes in tool diameters, cutting widths or cutting speeds did not affect the cutting performance values (Fig. 16).

On the basis of the conducted cutting tests it can be stated that the selection of cutting parameters and tool diameter does not affect the cutting performance, understood as cutting energy per unit of volume.

\section{COMPARISON OF RESEARCH RESULTS WITH CALCULATING ALGORITHMS}

Some of the largest tool companies: Sandvik Coromant (hereinafter Sandvik), Hoffmann Group - Garant (hereinafter Garant), Seco Tools (hereinafter Seco) create applications that are designed to help determine the cutting power during machining operations. After entering a certain number of parameters, the application is able to estimate the necessary power to perform cutting. 
The results of experimental studies with the algorithms of Seco and Garant were compared.

Computational algorithms of Garant and Seco take into account various factors in the assessment of the machine's power demand. Some factors are taken into account in both algorithms, which are: machining type, material grade, tool diameter, depth of cut, cutting width, feed per tooth, number of teeth and tool cutting speed. The Garant algorithm also takes into account blade material and tool wear, while the Seco algorithm takes into account the insert entering angle. This results in different values of the machine's power demand depending on the algorithm used.

For comparison with experimental data, the results from four data sets were used (the Seco algorithm did not include in its database the exact material used in the study):

- Garant algorithm for C45 + N steel and sharp tool (G1).

- Garant algorithm for C45 $+\mathrm{N}$ steel and weared tool (G2).

- Seco algorithm for easy-to-machine steel $\mathrm{Rm}$ 400-700 (S1).

- Seco algorithm for low-alloy steel Rm 550750 (S2).

Data from algorithms were compared with measured values of maximum power and average power during tests and the following maximal values of relative errors were obtained from measured values (Tab. 1).

Relatives errors were calculated as follows:

$$
\delta_{x}=\frac{\left|x-x_{0}\right|}{\left|x_{0}\right|} * 100 \%
$$

where: $\delta_{\mathrm{x}}$ - relative error [\%], $\mathrm{x}$ - actual values measured on the machine tool, $x_{0}-$ values obtained from algorithms

The presented results show that the differences between the actual values measured in the cutting process and the data from the algorithms differ significantly, and the machine's power demand predicted from the algorithms is inaccurate. It is worth noting that the Seco algorithms more accurately determined the power machine's demand, despite the fact that another material (with

Table 1. The maximum relative error from the values measured for the algorithms used

\begin{tabular}{|c|c|c|c|c|}
\hline Power/Algorithm & G1 & G2 & S1 & S2 \\
\hline Average power [\%] & 53 & 98 & 20 & 43 \\
\hline Maximum power [\%] & 31 & 70 & 28 & 23 \\
\hline
\end{tabular}

lower tensile strength) was used in the analysis than the one used in experimental research. The results indicate that there is a need to find a different, more accurate way to estimate the machine's demand for electrical power.

\section{CONCLUSIONS}

The presented research results show how difficult and complicated it is to obtain complete information on the power consumption of the machine tool during the cutting process. The selection of appropriate cutting parameters can significantly affect the machine's power demand. The tests show that obtaining a satisfactory surface roughness can be obtained by means of a wide range of cutting parameters, which have a compelling influence on the power consumption. Not only the cutting width and cutting speed, but also the tool diameter has a significant impact on energy and cutting power. Therefore, the above parameters should be chosen accordingly when planning the technological process, taking into account the resulting energy demand of the machine tool.

An important role in the machine tool's demand for power is the machine's construction itself and the method of power transmission. In the analyzed case of the vertical milling center, an important aspect was played by the gear employed during machining. Above 2,000 rpm, the machine was operating on the 2 nd gear, which resulted in a lower demand of the machine for electricity during time, when there was no contact with material. This type of knowledge can be useful in planning an energy-saving machining process.

During the trials, a coefficient was determined, which was called the cutting capacity. This parameter values proved to be very similar for all cutting tests made in experimental research. This information indicates that it is important to limit the power consumption of the machine tool during activities not related directly to the cutting process, such as machine operation time during the technological process, auxiliary work time, coolant pump working time, etc. The cutting capacity parameter can also be used to develop a method for assessing the machine's demand for electricity. Taking into account both the constant power consumption for machining and the power consumption of the machine for other activities, you can develop an algorithm that allows you to accurately estimate the machine's power demand. 
The reason for creating such an algorithm is shown by the comparison of experimentally determined data with the results of the applications of companies producing tools. The estimation of the power demand of a cutting machine without taking into account its properties and relying solely on data related to the workpiece, tool and cutting process results in committing significant errors in estimating the energy demand of the machine tool. For the tested machine, depending on the algorithm used, the relative error between the result of experimental tests and data from applications reached even $100 \%$.

The problem of energy consumption growing disproportionately to the increase in the number of people in the world causes that more and more emphasis is placed on seeking energy-saving solutions. Understanding the mechanisms responsible for the machine tool's demand for electricity can significantly reduce energy consumption in the machining industry, and a precise estimate of the machine's energy demand will allow better control of cutting processes.

\section{REFERENCES}

1. Behrendt T., Zein A., Min S.: Development of an energy consumption monitoring procedure for ma- chine tools CIRP-Annals Manufacturing Technology 61, 2012, 43-46.

2. Chudy R. ,Grzesik W.: Możliwości zmniejszenia energochłonności obróbki sekwencyjnej stali utwardzonej Mechanik vol.10/2016, 1462-1463.

3. Honczarenko J.: Ekologiczne obrabiarki Mechanik vol. 5-6/2012, 371-372.

4. Mori M., Fujishima M., Inamasu Y., Oda Y.: A study on energy efficiency improvement for machine tools CIRP Annals Volume 60, Issue 1, 2011, 145-148.

5. Newman S.T., Nassehi A., Imani-Asrai R., Dhokia V.: Energy efficient process planning for cnc machining CIRP Journal of Manufacturing Science and Technology Volume 5, Issue 2, 2012, 127-136.

6. Nosol A., Bartoszuk M., Winiarski P. Badania energochłonności procesu toczenia Zeszyty Naukowe Politechniki Rzeszowskiej 295, Mechanika z.89 (4/17), pażdziernik-grudzień 529-536.

7. Pieńkowski G., Krzyżanowski J., Mączka J.: Problem oceny energochłonności wyrobów wytwarzanych metodami obróbki ubytkowej Przegląd Mechaniczny R 2005, Nr11, 20-25.

8. Stembalski M.: Sposoby ograniczenia zużycia energii przez obrabiarki skrawające do metali Inż. Ap. Chem. 2010, 49(5), 107-108.

9. Terelak-Tymczyna A., Miądlicki K., Nowak M. Efektywność energetyczna procesu obróbki skrawaniem na przykładzie toczenia Mechanik vol.10/2016 1308-1309. 